\title{
SIMULASI SISTEM PARAMETER TERDISTRIBUSI MENGGUNAKAN METODE GARIS LATERAL DI LINGKUNGAN PSE SCILAB
}

\author{
A.D. Garnadi ${ }^{3}$, Verawati ${ }^{1,3}$, Prasetyaning Diah R.L ${ }^{2,3}$ \\ ${ }^{1}$ Institut Teknologi Bandung, Bandung, 40116 \\ 2 Institut Teknologi Bandung, Bandung, 40116 \\ ${ }^{3}$ Institut Pertanian Bogor, Bogor, 16680 \\ Email korespondensi : vera.math42@gmail.com, \\ prasetyaning.diah@gmail.com, agah.garnadi@gmail.com
}

\begin{abstract}
ABSTRAK
Pemodelan komputasional sudah menjadi hal umum sebagai prosedur yang esensial dalam analisis dinamika dari proses yang muncul di bidang sains dan rekayasa. Banyak dari proses ini merupakan sistem parameter terdistribusi, i.e., sistem dengan peubah keadaan bergantung kepada sejumlah peubah bebas (seperti ruang dan waktu) yang dinyatakan oleh sekumpulan persamaan differensial parsial (pdp). Metode garis lateral merupakan satu metode penyelesaian numerik pdp dengan cara menyelesaikan masalah syarat batas secara berturutan, dan tujuan tulisan ini ialah melaporkan pengembangan toolbox pdp berbasis-Scilab. Filosofi pengembangan ialah memberikan kepada pengguna dengan sebuah metode yang mudah dipahami dan sekumpulan contoh aplikasi yang dapat digunakan sebagai template Scilab untuk mengembangkan simulasi numerik di bidang baru. Dalam tulisan ini tiga buah ilustrasi yaitu, persamaan panas satu dimensi, model Opsi Jual Eropa, dan model perlakuan panas buah untuk membunuh serangga akan digunakan untuk memperlihatkan bagaimana template metode garis lateral digunakan untuk menyelesaikan permasalahan.
\end{abstract}

Keywords: Metode garis lateral, scilab, model simulasi.

\section{PENDAHULUAN}

Persamaan diferensial parsial parabolik, merupakan salah satu dari sekian banyak persamaan differensial yang sangat berperan dalam memodelkan berbagai masalah yang timbul dari ragam fenomena di sekitar kita. Meskipun beberapa persamaan panas yang tergolong sederhana dapat dicari solusi eksaknya, namun banyak permasalahan yang dimodelkan dalam persamaan panas dimana solusi eksak sulit dicari atau bahkan sama sekali tidak memiliki solusi eksak. Alternatifnya, bila solusinya ada dan tidak dapat diperoleh secara eksak, adalah dengan menyelesaikan persamaan panas tersebut secara numerik. Untuk itu dibutuhkan rutin (program) yang mampu menyelesaikan Persamaan Differensial Parsial (PDP) secara numerik. Namun hingga saat ini sedikit sekali perangkat lunak numerik yang menyediakan rutin untuk keperluan ini. Di lain pihak, rutin-rutin yang mampu menyelesaikan Persamaan Differensial Biasa (PDB) telah banyak berkembang dan sudah menjadi paket yang sudah jadi di hampir setiap perangkat lunak numerik yang ada saat ini. 
Tujuan tulisan ini menyajikan tutorial yang menunjukkan teknik penyelesaian persamaan panas secara numerik dengan memanfaatkan rutin numerik untuk menyelesaikan Masalah Syarat Batas (MSB) untuk PDB. Rutin yang digunakan adalah rutin yang tersedia di dalam Scilab yang bernama bvode. Untuk tutorial penggunaan serta keterangan mengenai bvode dapat dilihat pada [4]. Salah satu metode untuk menyelesaikan secara numerik persamaan evolusi, dikenal dengan metode garis $([8,9])$. Metode ini dilakukan dengan cara melakukan diskretisasi ruang dengan mempergunakan beda hingga ([9]) atau kolokasi ([8, 12]) misalnya, sehingga diperoleh sebuah masalah nilai awal untuk sebuah sistem PDB. Kemudian, dapat digunakan berbagai rutin numerik yang tersedia untuk menyelesaikan sistem PDB tersebut. Di dalam PSE komersial MATLAB disediakan pdepe untuk menyelesaikan persamaan parabolik 1-dimensi spasial, rutin ini didasarkan pada ([12]) yang mempergunakan metode kolokasi untuk diskretisasi ruang. Pendekatan lain untuk menyelesaikan persamaan diferensial parsial evolusi ialah menggunakan strategi diskretisasi waktu terlebih dulu, sehingga diperoleh MSB PDB untuk setiap langkah waktu. Dengan demikian, secara bertingkat diselesaikan secara berturutan harus diselesaikan MSB PDB. Teknik seperti ini sering sekali dikenal sebagai metode garis lateral, atau dikenal juga dengan metode Rothe. Dalam [7], terdapat ulasan singkat mengenai metode garis lateral ini. Salah satu tujuan tulisan ini ialah sebagai tutorial penggunaan perangkat lunak numerik untuk menyelesaikan persamaan diferensial parabolik secara umum. Tujuan lain dari tulisan ini ialah mendukung Indonesian Goes Open Source (IGOS) di bidang Scientific Computing, mengingat Scilab merupakan perangkat lunak yang bebas. Selain itu, tulisan ini sebagai langkah awal penyediaan perangkat alternatif dari perangkat lunak komersial MATLAB yang cukup populer, dimana tersedia pdepe. Tulisan ini disusun seperti berikut ini, pertama akan diingatkan terkait dengan persamaan panas. Kemudian secara singkat akan diperlihatkan diskretisasi waktu, sehingga diperoleh bentuk masalah syarat batas PDB untuk setiap langkah waktu diskret. Dengan demikian, bentuk ini dapat dikonversikan sehingga dapat diselesaikan dengan mempergunakan bvode dalam SCILAB. Dilanjutkan dengan bagian berikutnya yang memperlihatkan susunan lengkap implementasi metode garis lateral untuk menyelesaikan persamaan panas dan aplikasinya dalam SCILAB.

\section{BAHAN DAN METODE}

Pada makalah ini akan dibahas tiga ilustrasi, yaitu persamaan panas satu dimensi, model Opsi Jual Eropa, dan model perlakuan panas buah untuk membunuh serangga dengan menggunakan metode garis lateral.

\section{Persamaan Panas}

Jika pada waktu $t=0$ sebuah batang konduktor termal, selanjutnya kita katakan konduktor, dengan panjang $L$ memiliki suhu yang terdistribusi menurut rumus $Q_{0}=u_{0}(x)$, maka setelah beberapa saat suhu di batang tersebut akan terdistribusi pada batang konduktor menurut persamaan

$$
\begin{gathered}
\frac{\partial u(t, x)}{\partial t}=C \frac{\partial^{2} u(t, x)}{\partial x^{2}}, \\
0 \leq x \leq L, t \geq 0
\end{gathered}
$$


Sebagai tambahan, untuk $t \geq 0$, jika batang konduktor tersebut dipanasi atau didinginkan akibat adanya sumber panas $Q_{\text {cksemal }}=f(t, x)$, maka persamaan (1) akan menjadi

$$
\begin{gathered}
\frac{\partial u(t, x)}{\partial t}=C \frac{\partial^{2} u(t, x)}{\partial x^{2}}+f(t, x), \\
0 \leq x \leq L, t \geq 0
\end{gathered}
$$

Persamaan (1) dan (2) dikenal dengan nama persamaan panas dimana $C$ adalah diffusivitas termal benda yang dipanasi. Bersama dengan nilai-nilai awal yang diketahui, persamaan (1) dan (2) merupakan masalah syarat batas

$$
\begin{aligned}
& \frac{\partial u(t, x)}{\partial t}=C \frac{\partial^{2} u(t, x)}{\partial x^{2}}+f(t, x), \\
& 0 \leq x \leq L, t \geq 0 ; \\
& u(x, 0)=u_{0}(x), u(t, 0)=u_{a}, u(t, L)=u_{b} .
\end{aligned}
$$

dengan $u_{a}$ dan $u_{b}$ masing-masing menyatakan suhu pada ujung-ujung batang konduktor tersebut.

Dengan metode diskretisasi waktu, selang $t$ yang kontinu digantikan oleh titik-titik diskrit yang membentuk mesh. Turunan waktu yang ada pada persamaan (3) dihampiri dengan beda hingga (finite difference), sehingga persamaan (3) menjadi

$$
\begin{aligned}
& \frac{u^{k+1}(x)-u^{k}(x)}{\Delta t}=C \frac{d^{2} u^{k+1}(x)}{d x^{2}}+f^{k+1}(x), \\
& 0 \leq x \leq L, k=0,1,2, \ldots ; ; \\
& u^{0}(x)=u_{0}(x), u^{k+1}(0)=u_{a}, u^{k+1}(L)=u_{b} .
\end{aligned}
$$

Perhatikan bahwa persamaan (4) merupakan masalah syarat batas dari persamaan differensial biasa orde 2 yang dapat dicari solusi numeriknya menggunakan bvode untuk setiap langkah waktu ke $k$. Dengan menyusun kembali penulisannya, persamaan (4) akan menjadi

$$
\begin{aligned}
& \frac{d^{2} u^{k+1}(x)}{d x^{2}}=\frac{1}{C} \frac{u^{k+1}(x)-u^{k}(x)}{\Delta t}-f^{k+1}(x), \\
& 0 \leq x \leq L, k=0,1,2, \ldots ; \\
& u^{0}(x)=u_{0}(x), u^{k+1}(0)=u_{a}, u^{k+1}(L)=u_{b} .
\end{aligned}
$$

Persamaan differensial biasa (5) berorde 2. Dengan demikian, akibat diskretisasi pada langkah waktu, memungkinkan penggunaan bvode untuk mencari solusi numerik MSB, sehingga untuk setiap langkah waktu diperoleh profil distribusi panas.

\section{Model Opsi Jual Eropa}

Persamaan Black-Scholes biasa digunakan untuk mencari nilai opsi Eropa. Persamaan ini merupakan persamaan diferensial parsial berupa persamaan panas (parabolik) dengan syarat batas Dirichlet. Akan tetapi, yang diperhatikan di sini bukan waktu awalnya, melainkan waktu akhir. Ada banyak program yang dapat digunakan untuk menyelesaikan persamaan panas tetapi tulisan ini hanya akan membahas cara menyelesaikan persamaan panas dalam Scilab, khususnya untuk persamaan BlackScholes, dengan bvode. 
Untuk persamaan panas Black-Scholes didefinisikan waktu akhir suatu opsi $\tau=(T-t)$. Persamaan panas Black-Scholes berupa:

$$
\begin{aligned}
& \frac{\partial C}{\partial \tau}-\frac{1}{2} \sigma^{2} S^{2} \frac{\partial^{2} C}{\partial S^{2}}-r S \frac{\partial C}{\partial S}+r C=0 \\
& 0 \leq S \leq L, 0 \leq \tau \leq T
\end{aligned}
$$

dengan nilai awal:

$$
C(0, S)=\max (S(0)-E, 0)
$$

dan syarat batas:

$$
C(\tau, 0)=0, \quad C(\tau, S) \approx S-E e^{-r \tau}
$$

untuk $S$ yang besar.

Perhatikan bahwa persamaan (6) di atas memiliki bentuk yang mirip dengan persamaan panas

$$
\begin{aligned}
& \frac{\partial u(t, x)}{\partial t}=C \frac{\partial^{2} u(t, x)}{\partial x^{2}}+f(t, x) \\
& 0 \leq x \leq L, t \geq 0
\end{aligned}
$$

Dengan menuliskan

$$
\begin{aligned}
& a(S)=\frac{1}{2} \sigma^{2} S^{2} \\
& b(S)=r S \\
& c(S)=-r
\end{aligned}
$$

maka persamaan (6) dapat dituliskan lengkap bersama dengan nilai awal dan syarat batasnya dalam bentuk berikut:

$$
\begin{aligned}
& \frac{\partial C(\tau, S)}{\partial \tau}=a(S) \frac{\partial^{2} C(\tau, S)}{\partial S^{2}}+b(S) \frac{\partial C(\tau, S)}{\partial S}+c(S) C(\tau, S) \\
& 0 \leq S \leq L, 0 \leq \tau \leq T \\
& C(0, S)=\max (S(0)-E, 0), C(\tau, 0)=0, C(\tau, S) \approx S-E e^{-r \tau}
\end{aligned}
$$

Rutin bvode tidak dapat mencari solusi numerik persamaan (8) karena bentuknya yang parsial. Namun demikian, metode diskretisasi utuh memungkinkan penggunaan bvode untuk mencari solusi numerik persamaan panas.

Dengan melakukan diskretisasi pada waktu, selang $T$ yang kontinu digantikan oleh titik-titik diskrit yang membentuk mesh. Turunan terhadap waktu pada persamaan (8) digantikan dengan menggunakan pendekatan beda hingga, sehingga persamaan (8) menjadi

$$
\begin{aligned}
& \frac{C^{k+1}(S)-C^{k}(S)}{\Delta \tau}=a(S) \frac{d^{2} C^{k+1}(S)}{d S^{2}}+b(S) \frac{d c^{k+1}(S)}{d S}+c(S) C^{k+1}(S) \\
& S=0, \Delta S, 2 \Delta S, \ldots, L, k, k=0,1,2, \ldots \\
& C^{0}(S)=\max (S(0)-E, 0), C^{k+1}(0)=0, C^{k+1}(S) \approx S-E e^{-\tau t}
\end{aligned}
$$

Persamaan (9) dapat dicari solusi numeriknya menggunakan bvode secara iteratif dengan menganggap $k$ sebagai indeks iterasinya. Dengan memisahkan variabel-tak-bebasnya, persamaan (9) akan menjadi

$$
\begin{aligned}
& \frac{d^{2} C^{k+1}(S)}{d S^{2}}=\frac{1}{a(S)}\left(\frac{C^{k+1}(S)-C^{k}(S)}{\Delta \tau}-b(S) \frac{d c^{k+1}(S)}{d S}-c(S) c^{k+1}(S)\right) \\
& S=0, \Delta S, 2 \Delta S, \ldots, L, k=0,1,2, \ldots \\
& C^{0}(S)=\max (S(0)-E, 0), C^{k+1}(0)=0, C^{k+1}(S) \approx S-E e^{-r t}
\end{aligned}
$$

\section{Model perlakuan panas buah untuk membunuh serangga}

Di negara yang yang beriklim tropis seperti Indonesia ini, petani buah banyak dihadapi pada masalah pasca panen yaitu serangan hama larva 
serangga seperti ulat atau pun kutu. Penggunaan bahan kimia untuk mengatasi masalah ini akan membawa dampak buruk bagi kesehatan, sedangkan penggunaan control agent biologi yang merupakan antagonis potensial bagi hama tersebut membutuhkan biaya yang besar lagi sulit untuk diterapkan. Salah satu cara yang relatif murah dan mudah untuk mengatasi serangan hama larva serangga adalah dengan cara pencelupan buah ke dalam fluida (air) bersuhu cukup tinggi sehingga dapat membunuh hama tersebut. Permasalahan yang timbul adalah buah tidak boleh terlalu lama dicelup karena dikhawatirkan akan mengalami kerusakan fisik sehingga mengurangi kualitas buah tersebut. Petani dapat memperoleh waktu celup yang efektif untuk proses ini dengan cara mencoba beberapa kali pencelupan dan menerka berapa lama buah harus sudah diangkat agar hama bias diberantas tanpa merusak buah. Namun alangkah baiknya bila ada suatu cara cepat untuk mengetahui waktu celup efektif tanpa harus melakukan percobaan fisik, dengan catatan diketahui sifat fisik dan sifat termal buah. Tulisan ini juga memformulasikan suatu model matematika untuk tujuan memprediksi waktu celup yang efektif guna mendapatkan hasil terbaik pada proses pemberantasan hama dengan cara pencelupan buah ke medium bersuhu tinggi.

Akan dijelaskan model yang akan digunakan untuk model persamaan dalam buah ini. Proses konduksi panas pada suatu medium secara fisik dipengaruhi oleh koefisien disfusivitas panas, yaitu besaran yang menyatakan kemampuan medium untuk menghantarkan panas. Dengan mengasumsikan bahwa medium berbentuk batang, dapat dibuat suatu formulasi dalam bentuk persamaan diferensial yang secara matematis dapat menjelaskan proses konduksi panas. Menurut asumsi di atas hanya ada dua variabel bebas, yaitu $t$ dan $x$, yang masing masing menyatakan besaran waktu dan jarak (posisi di ruang) setiap titik pada medium berbentuk batang. Jika $\theta(t, x)$ adalah fungsi yang menyatakan besarnya temperatur medium pada waktu $t$ dan pada posisi $x$, maka konduksi panas dapat dinyatakan dalam bentuk

$$
\frac{\partial \theta}{\partial t}=\nabla \alpha \nabla \theta
$$

Keadaan panas yang tersebar pada awal pengamatan, yaitu pada saat $t=$ 0 , dinyatakan dalam bentuk persamaan nilai awal

$$
\theta(0, x)=\theta_{0}(x)
$$

Jika diasumsikan bahwa buah yang akan dicelupkan berbentuk bola berjarijari $R$ dan disfusivitas panas $\alpha$ konstan, maka persamaan (11) akan menjadi

$$
\frac{\partial \theta}{\partial t}=\alpha \frac{1}{r^{2}} \frac{\partial}{\partial r} r^{2} \frac{\partial \theta}{\partial r}
$$

dengan $r$ adalah variabel koordinat bola untuk buah yang akan dicelupkan.

Untuk menyatakan bahwa tidak ada laju perubahan suhu di pusat bola, yaitu pada $r=0$, dan bahwa suhu di permukaan buah pada saat dicelupkan adalah $T$, diperlukan dua syarat batas berikut

$$
\begin{gathered}
\left.\frac{\partial \theta}{\partial r}\right|_{r=0}=0 \\
\theta(t, R)=T .
\end{gathered}
$$


Meskipun persamaan diferensial (13) memiliki solusi analitik, akan tetapi bentuknya tidak dapat dijabarkan dalam bentuk fungsi elementer. Maka diperlukan solusi numerik. Karena persamaan (13) merupakan persamaan diferensial parsial, diperlukan diskretisasi sehingga dihasilkan persamaan diferensial biasa yang dapat diselesaikan menggunakan metode numerik. Dalam tulisan ini digunakan metode Rothe, atau dikenal dengan nama metode garis lateral [Ascher dkk, 1988], yaitu diskretisasi terhadap waktu $t$ terlebih dahulu dilakukan sehingga untuk setiap langkah waktu diperoleh masalah syarat batas persamaan diferensial biasa berikut

$$
\begin{gathered}
\frac{1}{\alpha} \frac{\theta^{k+1}(r)-\theta^{k}(r)}{\Delta t}=\frac{2}{r} \frac{d \theta^{k+1}(r)}{d r}+\frac{d^{2} \theta^{k+1}(r)}{d r^{2}}(16) \\
\frac{d \theta}{d r}(0)=0, \quad(17) \\
\theta^{k+1}(R)=T . \quad(18)
\end{gathered}
$$

Dengan demikian solusinya dapat dicari menggunakan metode yang dapat menyelesaikan masalah syarat batas persamaan diferensial biasa secara numerik. Di Scilab, sebuah perangkat lunak yang bebas, memiliki rutin untuk menyelesaikan masalah syarat batas sehingga metode Rothe dengan mudah dapat diimplementasikan.

\section{HASIL DAN DISKUSI}

Dari tiap ilustrasi yang telah dikemukakan pada bagian sebelumnya, akan dibahas tentang hasil apa yang diperoleh dengan menyelesaikan permasalahan di atas dengan menggunakan Scilab.

\section{Persamaan Panas}

Jika $\underline{z}$ menyatakan satu vektor baris berdimensi 2 yang memuat $u$ dan $u^{\prime}$

$$
\underline{z}=\left(\begin{array}{l}
\underline{z}_{1} \\
z_{2}
\end{array}\right)=\left(\begin{array}{c}
\underline{u} \\
\underline{u^{\prime}}
\end{array}\right)
$$

maka persamaan differensial pada persamaan (5) dapat didefinisikan sebagai berikut ini. Nomor-nomor di sebelah kiri sintaks adalah penomoran baris, bukan bagian dari sintaks.

01: function $f=f s u b(x, z)$

$02: f=(1 / C)^{*}(1 / \operatorname{tau})^{*}(z(1)-u 0(x))$;

03: endfunction

Langkah selanjutnya adalah menyusun syarat batas. Syarat batas pada persamaan (5) dapat dituliskan sebagai

$$
\begin{aligned}
& u^{k+1}(x)-u_{a}=0 \text { pada } x=0, \text { dan } \\
& u^{k+1}(x)-u_{b}=0 \text { pada } x=L .
\end{aligned}
$$

Sehingga sintaks untuk syarat batas persaman (5) adalah

01 : zeta $=[0, \mathrm{~L}]$;

02: function $\mathrm{g}=\mathrm{gsub}(\mathrm{x}, \mathrm{z})$

$03: f=[z(1)-u a, z(1)-u b] ; g=g(i)$;

04 : endfunction

Yang perlu diperhatikan adalah bahwa nilai batas $x=0$ dan $x=L$ dituliskan secara berurutan $(0 \leq z$ eta $(1) \leq z$ zeta $(2) \leq L)$. 
Selain dua fungsi di atas (fsub dan gsub), diperlukan pula dua fungsi yang merepresentasikan matriks Jacobi dari kedua fungsi tersebut (dfsub dan dgsub). Kedua fungsi ini didapat dengan cara menurunkan masing-masing fsub dan gsub terhadap $u$ dan $u$ '.

$$
\begin{aligned}
& \mathrm{dfsub}=\mathrm{Jac}(\mathrm{fsub})=\left(\begin{array}{ll}
\frac{\partial \mathrm{fsub}}{\partial u} & \frac{\partial \mathrm{fsub}}{\partial u^{\prime}}
\end{array}\right) \\
& =\left(\begin{array}{ll}
\frac{\partial \mathrm{fsub}}{\partial z(1)} & \frac{\partial \mathrm{fsub}}{\partial z(2)}
\end{array}\right) \\
& \operatorname{dgsub}=\mathrm{Jac}(\text { gsub })=\left(\begin{array}{cc}
\frac{\partial g \mathrm{sub}_{1}}{\partial u} & \frac{\partial g \mathrm{sub}_{1}}{\partial u^{\prime}} \\
\frac{\partial g \mathrm{sub}_{2}}{\partial u} & \frac{\partial g \mathrm{sub}_{2}}{\partial u^{\prime}}
\end{array}\right) \\
& =\left(\begin{array}{ll}
\frac{\partial g \operatorname{sub}(1)}{\partial z(1)} & \frac{\partial g \operatorname{sub}(1)}{\partial z(2)} \\
\frac{\partial g \operatorname{sub}(2)}{\partial z(1)} & \frac{\partial g \operatorname{sub}(2)}{\partial z(2)}
\end{array}\right)
\end{aligned}
$$

Maka script rangkaian perintah untuk matriks-matriks di atas adalah

01: function $\mathrm{df}=\mathrm{dfsub}(\mathrm{x}, \mathrm{z})$

$02: \mathrm{df}=\left[1 / \mathrm{C}^{*} \operatorname{tau}, 0\right]$;

03: endfunction

04 : function $\mathrm{dg}=\mathrm{dgsub}(\mathrm{x}, \mathrm{z})$

$05: d g=[1,0 ; 1,0] ; d g=d g(i,:)$

06: endfunction

Diberikan sebuah contoh kasus persamaan panas sederhana seperti berikut. Diketahui sebuah batang konduktor dengan panjang $L=1$ dengan diffusivitas termal konduktor tersebut $C=8.5$. Pada saat $t=0$ dimisalkan distribusi panas pada batang konduktor tersebut diberikan oleh $Q_{0}=5 \sin (x)$. Panas di ujung kiri dan kanan selalu bernilai 0. Akan digambarkan perubahan distribusi panas pada batang konduktor tersebut hingga $t=7$.

Model permasalahan ini dapat dituliskan sebagai persamaan seperti berikut ini

$$
\begin{aligned}
& u_{t}=8.5 u_{x x} \\
& 0 \leq x \leq 1,0 \leq t \leq 10, \\
& u(0, x)=5 \sin (x), u(t, 0)=0, u(t, 1)=0 .
\end{aligned}
$$

dan dengan mengambil $\Delta x=0.1$ dan $\tau=\Delta t=1$, berikut adalah gambar grafik dua dimensi perubahan distribusi panas untuk masalah di atas.

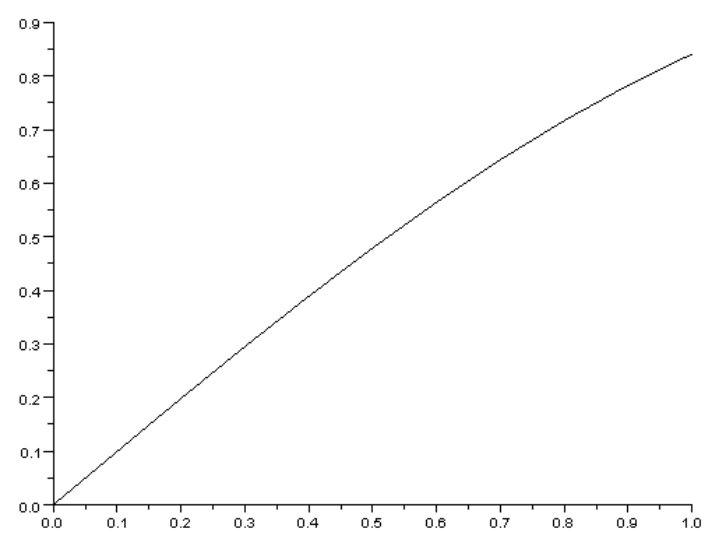


Gambar 1. Evolusi distribusi batang untuk sejumlah waktu diskret divisualisasi dalam satu bidang gambar.

\section{Model Opsi Jual Eropa}

Dari bagian sebelumnya persamaan differensial biasa (10) berorde 2 . Misalkan $\underline{z}$ adalah suatu vektor (kolom) berdimensi 2 yang memuat $C$ dan $C^{\prime}$

$$
\underline{z}=\left(\begin{array}{l}
z_{1} \\
z_{2}
\end{array}\right)=\left(\begin{array}{c}
\underline{c} \\
\underline{c}^{\prime}
\end{array}\right) \text {. }
$$

Karena persamaan differensial biasa (10) yang dihasilkan dari pendiskretisasian (9) berorde 2 maka persamaan (10) dapat dinotasikan sebagai $f\left(\tau, C(\tau, S), C^{\prime}(\tau, S)\right)$. Dengan menggunakan pemisalan di atas, notasi persamaan (10) menjadi $f(\tau, \underline{z})$.. Dalam Scilab, semua variabel berstruktur data array. Karena vektor , $\underline{z}$, dapat direpresentasikan dalam bentuk array, maka kita dapat dengan mudah mendefinisikan persamaan (10) dalam bentuk fungsi Scilab seperti berikut. Nomor-nomor di sebelah kiri sintaks adalah penomoran baris, bukan bagian dari sintaks.

01: function $\mathrm{f}=\mathrm{fsub}(\mathrm{S}, \mathrm{z})$

02: $f=(1 / a(S))^{*}(\ldots$

03: $\quad(1 / \mathrm{tau})^{*}(\mathrm{z}(1)-\mathrm{C}(\mathrm{S})) \ldots$

04: $\quad-b(S)^{*} z(2) \ldots$

05: $\quad-c(S)^{*} z(1) \ldots$

06: $\quad)$;

07: endfunction

Langkah selanjutnya adalah menyusun syarat batas. Syarat batas pada persamaan (10) dapat dituliskan sebagai

$$
\begin{aligned}
& C^{k+1}(S)=0 \quad \text { pada } S=0, \text { dan } \\
& C^{k+1}(S)-S+E e^{-r \tau} \quad \text { pada } S \approx L
\end{aligned}
$$

sehingga sintaks untuk syarat batas persamaan (10) adalah

01: zeta $=[0, \mathrm{~L}]$;

02: function $g=g s u b(S, z)$

03: $g=\left[z(1), z(1)-L+E^{\star} \operatorname{Exp}\left(-r^{\star} t a u\right)\right.$;

04: $g=g(i)$;

05: endfunction

Yang perlu diperhatikan adalah bahwa nilai batas $S=0$ dan $S=L$ dituliskan secara berurutan $(0 \leq z$ zeta $(1) \leq$ zeta $(2) \leq L)$.

Selain dua fungsi di atas (fsub dan gsub), diperlukan pula dua fungsi yang merepresentasikan matriks Jacobi dari kedua fungsi tersebut (dfsub dan dgsub). Kedua fungsi ini didapat dengan cara menurunkan masing-masing fsub dan gsub terhadap $C$ dan $C$.

$$
\begin{aligned}
& \mathrm{dfsub}=\mathrm{Jac}(\mathrm{fsub})=\left(\begin{array}{ll}
\frac{\partial \mathrm{fsub}}{\partial C} & \frac{\partial \mathrm{fsub}}{\partial C^{\prime}}
\end{array}\right)=\left(\begin{array}{ll}
\frac{\partial \mathrm{fsub}}{\partial z(1)} & \frac{\partial \mathrm{fsub}}{\partial z(2)}
\end{array}\right) \\
& \operatorname{dgsub}=\mathrm{Jac}(\text { gsub })=\left(\begin{array}{ll}
\frac{\partial \operatorname{gsub}_{1}}{\partial C} & \frac{\partial g \operatorname{sub}_{1}}{\partial C^{\prime}} \\
\frac{\partial g \operatorname{sub}_{2}}{\partial C} & \frac{\partial g \operatorname{sub}_{2}}{\partial C^{\prime}}
\end{array}\right)=\left(\begin{array}{ll}
\frac{\partial g \operatorname{sub}(1)}{\partial z(1)} & \frac{\partial g \operatorname{sub}(1)}{\partial z(2)} \\
\frac{\partial g \operatorname{sub}(2)}{\partial z(1)} & \frac{\partial g \operatorname{sub}(2)}{\partial z(2)}
\end{array}\right)
\end{aligned}
$$

Sintaks untuk matriks-matriks di atas adalah 
01: function $\mathrm{df}=\mathrm{dfsub}(\mathrm{S}, \mathrm{z})$

$02: \mathrm{df}=[(1 / \mathrm{tau})-\mathrm{c}(\mathrm{S}) / \mathrm{a}(\mathrm{S}),-\mathrm{b}(\mathrm{S}) / \mathrm{a}(\mathrm{S})]$;

03: endfunction

04: function $\mathrm{dg}=\mathrm{dgsub}(\mathrm{S}, \mathrm{z})$

05: $d g=[1,0 ; 1,0] ; \operatorname{dg}=\mathrm{dg}(\mathrm{i},:$ );

06: endfunction

Berikut diberikan contoh numerik menyelesaikan persamaan Black-Scholes dengan cara menyusun beberapa fungsi dan setting variabel yang menjadi argumen bagi bvode. Diberikan $E=4, \sigma=0.5, r=0.03, T=1, N S=11$, $N T=29$, dan $L=10$, berarti $k=\Delta T=T / N T$ dan $h=\Delta S=L / N S$. Permasalahan ini dapat dimodelkan sebagai berikut:

$$
\begin{aligned}
& \frac{\partial C(\tau, S)}{\partial \tau}=\frac{1}{2}(0.5)^{2} S^{2} \frac{\partial^{2} C(\tau, S)}{\partial S^{2}}+0.03 S \frac{\partial C(\tau, S)}{\partial S}-0.03 C(\tau, S) \\
& 0 \leq S \leq 10,0 \leq \tau \leq 1 \\
& C(0, S)=\max (S(0)-E, 0), C(\tau, 0)=0, C(\tau, S) \approx S-E e^{-r \tau}
\end{aligned}
$$

Contoh di atas menghasilkan grafik perubahan nilai opsi (Black-Scholes) dari waktu ke waktu dalam bentuk dua dimensi (Gambar 2) maupun tiga dimensi (Gambar 3) seperti berikut.

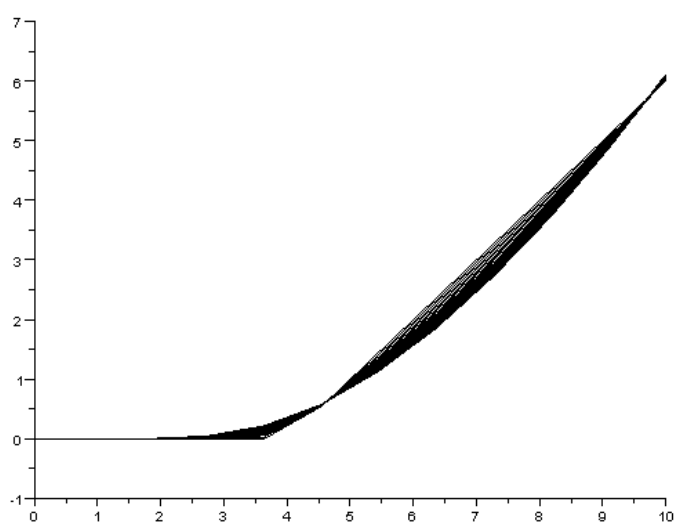

Gambar 2. Perubahan nilai opsi (Black-Scholes) dari waktu ke waktu dalam bentuk dua dimensi



Gambar 3. Perubahan nilai opsi (Black-Scholes) dari waktu ke waktu dalam bentuk tiga dimensi 


\section{Model perlakuan panas buah untuk membunuh serangga}

Model simulasi dalam tulisan ini diterapkan pada buah apel malang (Malus Sylvestris Mill) dengan dua perlakuan, masing-masing perlakuan menggunakan suhu medium celup yang berbeda.

3.1 Apel Malang. Buah yang digunakan dalam percobaan ini adalah buah apel malang yang diasumsikan berbentuk bola. Asumsi untuk suhu awal apel adalah homogen sebesar $29^{\circ} \mathrm{C}$. Dalam tulisan ini dilakukan dua kali simulasi, masing-masing dengan suhu medium (air) sebesar $47^{\circ} \mathrm{C}$ dan $60^{\circ} \mathrm{C}$ dengan catatan bahwa suhu medium adalah homogen dan dijaga tetap sepanjang waktu. Dengan kadar air apel $83.33 \%$, didapat besaranbesaran konduktivitas panas sebesar $0.005979 \mathrm{Watt} / \mathrm{cm}^{\circ} \mathrm{C}$ dan disfusivitas panas $2.0990 \times 10^{-3} \mathrm{~cm}^{2} / \mathrm{dtk}$. [Fahmi, 2004].

3.2 Lalat Buah (Rhagoletis Pomonella). Menurut Fields (2002), suhu mematikan bagi serangga terletak pada rentang yang dapat dilihat pada tabel berikut.

Tabel 1. Efek temperatur letal serangga

\begin{tabular}{|c|c|}
\hline $\begin{array}{c}\text { Rentang } \\
\text { temperatur } \\
\text { mematikan }\left({ }^{\circ}\right) \mathrm{C}\end{array}$ & Efek \\
\hline Di atas 62 & $\begin{array}{c}\text { Mati kurang dari } \\
1 \text { menit }\end{array}$ \\
\hline 50 hingga 62 & $\begin{array}{c}\text { Mati kurang dari } \\
1 \text { jam }\end{array}$ \\
\hline 45 hingga 50 & $\begin{array}{c}\text { Mati kurang dari } \\
1 \text { hari }\end{array}$ \\
\hline 35 hingga 42 & $\begin{array}{c}\text { Serangga mulai } \\
\text { mencari tempat } \\
\text { yang lebih dingin }\end{array}$ \\
\hline
\end{tabular}

Tulisan ini mengasumsikan larva lalat buah hidup pada daerah yang tidak lebih dalam daripada $0.5 \mathrm{~cm}$ dari kulit buah. Dari data-data tersebut dapat dilakukan simulasi pencelupan buah dengan menggunakan metode numerik. Dengan menggunakan software Scilab, solusi numerik persamaan panas di atas dapat digunakan untuk memprediksi waktu celup efektif.

Berikut ini disajikan hasil simulasi dua kasus untuk suhu medium yang berbeda.

Kasus Pertama. Dengan mengambil suhu medium luar sebesar $47^{\circ} \mathrm{C}$ didapatkan hasil dalam bentuk kurva sebaran panas seperti berikut. Simulasi dilakukan dengan mengambil langkah waktu 5 menit, selama 80 menit. Suhu awal buah dianggap sama dengan suhu ruang yaitu $29^{\circ} \mathrm{C}$. 




Gambar 4. Hasil simulasi dengan suhu medium $47^{\circ} \mathrm{C}$

Kasus Kedua. Dengan mengambil suhu medium sebesar $60^{\circ} \mathrm{C}$ didapatkan hasil dalam bentuk kurva sebaran panas seperti berikut. Seperti halnya kasus pertama, langkah waktu, jangka waktu dan suhu awal buah kita ambil sama.

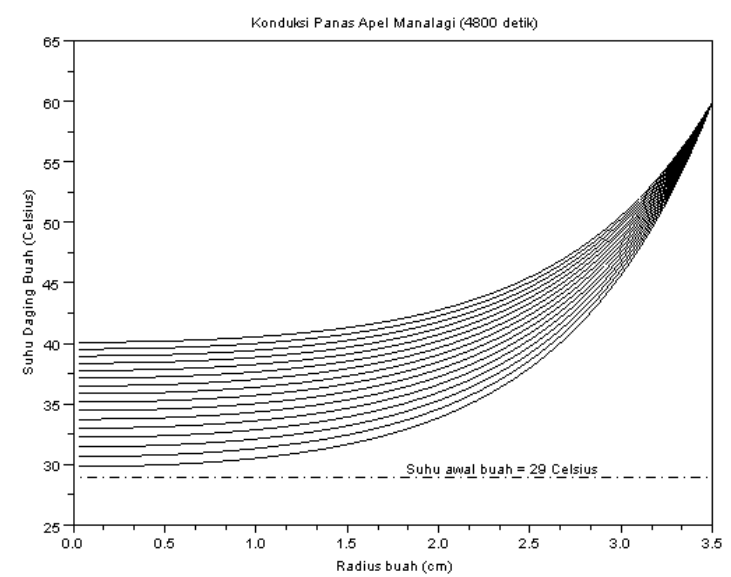

Gambar 5. Hasil simulasi dengan suhu medium $60^{\circ} \mathrm{C}$

Untuk kasus pertama, di akhir simulasi diketahui bahwa suhu pada kedalaman $0.5 \mathrm{~cm}$ dari kulit buah mencapai sekitar $41.5^{\circ} \mathrm{C}$. Artinya, menurut tabel 1, bahwa proses pencelupan untuk kasus pertama ini gagal mengusir serangga yang ada pada kedalaman tersebut. Serangga yang terusir akibat proses pencelupan ini hanyalah serangga yang ada hingga kedalaman 0.7 $\mathrm{cm}$ dari kulit buah. Karena dikhawatirkan bahwa jika waktu pencelupan buah diperpanjang maka akan mengakibatkan kerusakan fisik buah, maka yang perlu dilakukan adalah menaikkan suhu medium tempat buah dicelup. Pada kasus kedua diperoleh bahwa setelah buah dicelupkan selama 80 menit, suhu pada kedalaman $0.5 \mathrm{~cm}$ dari kulit mencapai $51^{\circ} \mathrm{C}$. Kembali mengacu pada tabel 1, dapat diketahui bahwa serangga yang hidup hingga kedalaman tersebut dapat terusir oleh penetrasi panas yang terjadi akibat proses pencelupan. Kesimpulan Proses pencelupan buah ke dalam medium bersuhu tinggi dapat dilakukan guna mengusir serangga yang berpotensial hidup dalam daging buah. Namun perlu diperhatikan bahwa penetrasi panas yang terjadi akibat proses ini dapat menyebabkan kerusakan fisik buah yang pada akhirnya akan menurunkan kualitas buah. Untuk itu suhu medium dan 
waktu celup harus diambil sedemikian sehingga serangga yang hidup dalam daging buah dapat diusir tanpa merusak buah. Simulasi menggunakan model persamaan panas dapat digunakan untuk mengetahui kombinasi yang tepat antara suhu medium dan waktu celup sehingga proses pencelupan memberikan hasil yang optimal.

\section{KESIMPULAN}

Telah didemonstrasikan implementasi penyelesaian numerik persamaan differensial parsial evolusi dengan satu dimensi spasial dalam SCILAB dengan memanfaatkan rutin untuk menyelesaikan masalah syarat batas yang disediakannya.

Terbuka kesempatan pengembangan teknik metode garis lateral sebagai pustaka numerik di lingkungan SCILAB, menjadi pustaka yang setara dengan pdepe dengan mengikuti rancangan yang digariskan oleh Schryer [11] . Dengan kerangka yang diberikan Schryer tersebut, dimungkinkan memanfaatkan metode ini untuk menyelesaikan berbagai aplikasi dari persamaan panas, model opsi jual Eropa, dan model perlakuan panas buah untuk membunuh serangga.

\section{DAFTAR PUSTAKA}

[1] Ascher, U., J. Christiansen, and R.D. Russel. 1981. Collocation Software for Boundary Value ODEs, ACM Transactions on Mathematical Software, Vol.7, No.2.

[2] Ascher, U., R. M. Mattheij, and R.D Russel. 1988. Numerical Solution of Boundary Value Problem, New Jersey: Prentice-Hall.

[3] Campbell, S.L., J.P. Chancelier, and R.. Nikoukhah. 2005. Modeling and Simulation in Scilab/Scicos, Springer.

[4] Ekastrya, D., F. Ayatullah dan A.D. Garnadi. 2006. Menyelesaikan Persamaan Differensial Biasa - Syarat Batas dalam Scilab menggunakan bvode. JMA v7n1, 1-10.

[5] Fahmi, A. 2004. Kajian Penetrasi panas pada buah apel (Malus Sylvestris Mill) selama proses heat treatment. Tesis (Pascasarjana)-Institut Pertanian Bogor.

[6] Fields, P.G. 2002. Alternatives to Methyl Bromide Treatments for StoredProduct and Quarantine Insects. Annu. Rev. Entomol, 47:X.X. Cereal Research Centre, Agriculture and Agri-Food Canada.

[7] Garnadi, A.D. 2004. Masalah Syarat Batas Bebas Persamaan Diferensial Parsial Parabolik Satu Dimensi. JMA, v3n2, pp-pp.

[8] Madsen, N.K. and R.F. Sincovec. 1979. ALGORITHM 540: PDECOL, General Collocation Software for Partial Differential Equations, ACM Transactions on Mathematical Software, Vol. 5, No.3, 326-327.

[9] May, R.L. 1990. Numerical Solution of PDE's using The Methods of Lines, TR No. 2, Dept. Math., RMIT.

[10] Poulikakos, D. 1994. Conduction Heat Transfer, New Jersey: PrenticeHall International. 
[11] Schryer, N.L. 1990. Designing Software for One-Dimensional Partial Differential Equations, ACM Transactions on Mathematical Software. Vol. 16, No.1,72-85.

[12] Skeel, R.D. and M. Berzins. A Method for the Spatial Discretization of Parabolic Equations in One Space Variable, SIAM J. Sci.Stat.Comp., v11, 132.

[13] Wirakartakusumah, M.A., K. Abdullah dan A. M. Syarif. 1992. Sifat Fisik Pangan. Departemen pendidikan dan Kebudayaan, Direktorat Jenderal Pendidikan Tinggi Pusat antar Universitas Pangan dan Gizi, Bogor: Institut Pertanian Bogor. 